\title{
FLORA CONTAMINANTE DOS PRODUTOS EMBUTIDOS DE CARNE, TIPO SALAME, COM ESPECIAL REFERENCIA AOS MICRORGANISMOS DO GENERO LACTOBACILLUS (BEIJERINCK, 1901)
}

\author{
Raphael Valentino RICCETTI * \\ Omar J. Marzagão BARBUTO * \\ José Cezar PANETTA***
}

\section{RFMVA-7}

RICCETTI, R. V. et al. - Flora contaminante dos produtos embutidos de carne, tipo salame, com especial referéncia aos microrganismos do gênero Lactobacillus (Beijerinck, 1901). Rev. Fac. Med. vet. Zootec. Univ. S. Paulo, 9:9\$-106, 1972.

RESUMo - Contribuindo para o estudo da flora contaminante dos produtos embutidos de carne, especialmente daqueles classificados como salames, os Autores pesquisaram os germes pertencentes aos Gêneros Micrococcus e Lactobacillus, considerados de importancia no processo de maturação desses alimentos. Foram estabelecidas, entre outras condições: 1.a) a evolução numérica desses microrganismos nas várias etapas de maturacão; 2.a) a supremacia das espécies desses generos; $\left.3 .{ }^{a}\right)$ o otimo de temperatura, considerado simultaneamente com o comportamento bioquimico da maioria das cepas.

UNITERMos: Salame; embutidos * "Lactobacillus *; Maturação*.

\section{INTRODUCAO}

A flora microbiana existente nos produtos cárneos embutidos possui relevante papel de ordem tecnológica e higiênico-sanitária, pois, como é sabido, o seu controle quantitativo e qualitativo assegura, além de um excelente produto, no que diz despeito às suas qualidades físico-organoléptí- cas, um produto de elevadas propriedades higiênicas. Dessarte, existe, como facilmente se depreende, uma grande interrelação entre os fatores tecnológico e higiênico-sanitário da produção, nunca podendo haver superação de um em detrimento do outro; efetivamente, a somatória desses fatores assegurarão produtos de ótima qualidade e isentos de problemas pertinentes à saúde pública. Tal correlação é perfeitamente caracterizada, quando se estuda a microbiologia dos produtos cárneos embutidos, particularmente daqueles cuja tecnologia implica numa longa maturação, como é o caso dos salames de modo geral, nos quais, a par de agentes microbianos patogênicos, constata-se a presença de germes banais, além de uma flora extremamente útil no que respeita ao seu número e, principalmente, pelas suas ações metabólicas, que redundam na obtençāo de produtos finais com especificas caracteristicas de gosto, odor, textura e conservação.

Portanto, sumamente importantes para o aperfeiçoamento tecnológico e higiênicosanitário dos produtos cárneos embutidos, são os estudos em torno da flora microbiana que eventualmente pode contaminá-los ou que a êles, propositadamente, seja adicionada com a finalidade de se obter adequada maturação.

- Professor Assistente.

* Professor-Livre-Docente.

** Professor-Assistente-Doutor Departamento de Medicina Preventiva e Saủde Anlmal da Faculdade de Medicina Veterinária e Zootecnla da Universidade de Sāo Paulo. 
RICCETTI, R. V. et al. - Flora contaminante dos produtos embutidos de carne, tipo salame, com especlal referêncla aos microrganismos do gênero Lactobacillus (Bcljerinck, 1901) Rev. Fac. Med. vet. Zootec. Univ. S. Paulo, 9:93-106, 1972.

Assim, os números, as espécies, as predominâncias e a seleção dos microrganismos que habitam tais produtos, são informações que forçosamente devem ser procuradas $e$ pesquisadas, quando se pretende evoluir nesse campo da industrialização da carne.

Um fato bastante conhecido, compreendido facilmente ao compulsar-se a literatura especializada, é o de existir, durante a maturação dos produtos, verdadeira scleção, iniciando-se com grande e variada população microbiana, para um posterior processo regressivo de determinadas espécies e um aumento pronunciado de outras. Estabelece-se, dessa forma, verdadeira competição entre as espécies, representadas, no início, por microflora heterogênea e que, depois, vai sendo substituída por uma flora mais especifica, a qual culmina, devido a uma série de transformações metabólicas, bioquímicas e ambientais, na existência, quase que exclusiva, de representantes de dois importantes generos: Mrcrococcus e LACTOBACILLUS.

Deve-se notar, entretanto, que a presença de Lactobacillus sp., somente se torna útil, caso o seu número não supere certos limites; quando a quantidade dessas bactérias supera o limite de $1 \mathrm{milhão/grama,}$ forma-se uma quantidade excessiva de ácido lático, o que leva o produto a apresentar alterações de gosto. Os principais responsáveis por essa acidificaçāo exagerada são as cepas homo-fermentativas fortemente acidificantes de LACTOBACILLUS $s p$.. Mas, é importante também assinalar que os LACTOBACILLUS estão sempre presentes nos produtos cárneos embutidos, constituindo-se em habitantes normais desses produtos, motivo pelo qual, cuidados higiênicosanitários especiais devem ser tomados nos estabclecimentos produtores, por não se poder, simplesmente, preconizar a eliminação total das bactérias existentes nos locais de manipulação dos produtos cárneos pois, como parece demonstrado, se algumas bactérias têm importância no processo de maturação, é óbvio que devam ser tomdaas medidas de caráter higiênico, a fim de evitar excessiva contaminação.
Porém, a maior importáncia do perfeito conhecimento dessa flora, para fins industriais, ao lado do controle higiênico-sanitário, é a tentativa de se produzir, em futuro próximo, "starters" de culturas puras dos germes citados, o que possibilitará a elaboração de produtos sob condiçōes constantes e, portanto, de qualidade maior.

Buscou-se no presente trabalho, colaborar para o aprimoramento e padronização das técnicas de maturação, tendo em vista, principalmente, a quantidade do produto elaborado, a diminuição do tempo de maturação e a melhoria das condições higiênico-sanitárias de fabricaçāo das substâncias elaboradas. A diminuição do tempo de maturação, além de produzir vantagem econômica visa, aliada à modernização da técnica, introduzir processos de maturação mais adequados $c$ melhor controlados, tentando-se, assim, eliminar certos procedimentos empiricos e tradicionais.

bem verdade que os procedimentos tradicionais de elaboraçāo e tratamento dos produtos embutidos, bem como de outros produtos cárneos, sofreram influência fundamental com o avanço tecnológico da indústria. Porém, muito embora arraigados a uma mecânica rudimentar, que envolvia, automaticamente, um rendimento baixo, esses procedimentos eram caracterizados por uma qualidade rclativamente alta, situação esta contrastante com a mecânica atual, qual seja, a de um alto rendimento industrial, para fazer frente aos requisitos de mercado, mas pecando pela qualidade, que já não pode acompanhar o grau de rendimento. Não seria, pois, exagêro afirmar-se que à medida que foram se aperfeiçoando os sistemas de fabricação dos produtos embutidos, automaticamente, dentro de certos limites, foi baixando a sua qualidade, sem que deva ser responsabilizada exclusivamente a indústria por esta situação, mas a um conjunto de fatores econômicos, sociais e ambientais, que levaram a indústria a se preocupar mais com a quantidade do que com a qualidade.

Portanto, são altamente valiosos os estudos que visam a melhoria da qualidade dos 
RICCETTI, R. V. et al. - Flora contaminante dos produtos embutidos de carne, tipo salame, com especial referêncla aos microrganismos do gênero Lactobacillus (Beijerinck, 1901) Rev. Fac. Med. vet. Zootec. Univ. S. Paulo, 8:93-106, 1972.

produtos cárneos embutidos, no afã de se atender ,a um tempo, a preocupação da indústria em produzir cada vez mais, para atender aos mercados consumidores, como também salvaguardar a qualidade dos produtos, a ponto de não ameaçar o seu padrão, pela exageradı preocupação de simplesmente produzir.

Tais estudos devem prender-se, primeiramente, a um melhor conhecimento dos produtos elaborados, no que diz respeito à sua tecnologia, à sua conservação e, principalmente, à sua maturação. Inscrido neste avanço e tendo-se levado $\mathrm{cm}$ conta todos os fatores acima descritos, objetivou-se, neste trabalho, reunir dados concernentes aos gêneros e, na medida do possivel, às espécies ligadas aos fenómenos expostos, primeiro passo para um estudo mais aprofundado. Com tal finalidade, procurou-se estabelecer os gradientes de contaminação de um produto típico (salame, tipo salaminho), desde o momento da elaboração, até uma idade de 60 dias, com intervalos compreendidos de 10 em 10 dias, mantidos em ambiente de maturação. Paralelamente, procurou-se identificar morfológica LACTOBACILLUS e MICrococcus, durante as variadas fases de maturaçāo. Tentou-se, ainda, a identificação de algumas espécies do gênero LACTOBACILLUS, considerado de grande importáncia no processo biológico da maturação.

\section{LITERATURA}

As modificações organolépticas provenientes do metabolismo bioquímico da flora bacteriana útil dos produtos embutidos de longa "cura", é de notável importância e tem sido motivo de estudos, por parte de inümeros pesquisadores. Buscando aprofundar-se no assunto GIANELLI \& (1953), revelou que a microflora dos produtos embutidos (salame tipo Milano), atinge a um máximo entre os 18 e 27 dias de maturação, para depois decrescer ao redor do $54 .^{\circ}$ dia, presumivelmente devido à perda da umidade do produto. Aliás, de grande importância é o estudo de GIANELLI 6 (1953), no que respeita ao comportamento das bactérias do grupo COLI-AEROGENES: inicialmente seu número é grande, sofrendo, cm seguida, brusca queda ao redor do $8 .^{\circ}$ dia, nāo sendo mais encontrados depois de 16 dias de maturação, situação esta, provocada pela seleção natural que se processa no produto durante sua "cura".

Por outro lado, CORETTI et col. 3 (1956), demonstraram cabalmente que no inicio da maturação, a população microblana dos produtos embutidos é constitulda quase que totalmente por Micrococcus sp., havendo, com o passar do tempo, um decréscimo destes e um aumento progressivo das bactérias do gênero Lactobacillus.

Também NIINIVARA \& POHJA 11 (1964), ao estudarem o processo de maturação dos embutidos, isolaram de salsichas defumadas numerosas cepas e notaram prevalência inicial de Micrococcus, que foram substituídos, com o tempo de maturação, por cepas de LACTOBACILLUS sem haver, entretanto, grande diminuíção da carga bacteriana total. Por outro lado, constataram estes autores, a importância do conhecimento destes germes tanto na maturação como no aspecto higiênico-sanitário dos produtos, propondo com vantagens o seu uso, como "starters". Ainda com o mesmo propósito GIOLITTI 7 (1960), revelou que, no inicio da maturação, logo após o produto ser elaborado, existe uma flora heterogênea, composta de bactérias das mais variadas espécies que invadem a massa dos embutidos em conseqüência das manipulações tecnologicas a que estes são submetidos; no periodo inicial da maturação, as condiçōes ambientais são extremamente favoráveis ao desenvolvimento desta flora que, encontrando condições btimas de umidade e elementos nutritivos, multiplica-se com grande intensidade. Concomitantemente a essas bactérias inespecificas, uma flora especifica, no início mascarada pelo crescimento da primeira, começa a evidenciar-se de forma mais nítida, devido às mudanças de crescimento que se alteram com o decorrer da maturação, ou seja, diminuição da umidade 
RICCETTI, R. V. et al. - Flora contaminante dos produtos embutidos de carne, tipo salame, com especlal referencla aos microrganismos do genero Lactobacillus (Beljerinck, 1901) Rev. Fac. Med. vet. Zootec. Univ. S. Paulo, 9:93-106, 1972.

e conseqüente aumento da concentraçăo de cloreto de sódio.

Estudo paralelo e relevante é o de GIOLITTI \& MASSACRA \& (1963), que concluem ser a produção do aroma devida principalmente a um processo de degradação de origem bacterlana, das gorduras presentes na massa. Segundo esses autores, os $\mathrm{MI}$ Crococcus, escassos ao inicio e aumentando notadamente com o decorrer da maturação, atuam principalmente desdobrando as gorduras em ácidos graxos, além de atuarem fornecendo fatores de crescimento, indispensávels para os LACTOBACILI.us se multiplicarem com mais facilidade. Enfim, a presença de ácidos graxos livres e o aumento da concentraçāo salina, provocam um efeito inibidor sobre a multiplicaçāo de germes GRAM negativos, predominantes no inicio. importante relacionar esses dados com o de SHARPE 14 (1966), que observou a ação dos LACTOBACSLlus na carne, verificando sua adaptação à concentraçōes elevadas de cloreto de sódio e às baixas temperaturas. Além disso, constatou que a elevada concentraçāo de cloreto de sódio favorece diretamente a multiplicação dos LACTOBACILLUS halotolerantes $e$, ao mesmo tempo, inibe o crescimento de outras bactérias que poderão obstar o desenvolvimento dos primeiros; o ácido lático que é produzido pelas cepas homofermentativas do LACTOBACILLUS faz baixar o pH, eliminando, assim, as bactérias nāo acidófilas e levando ao estabelecimento de uma florabacterlana constituida principalmente de LACTOBACILLUS. O próprio SHARPE \& FRYER is (1966), verificou que a produção de pequenas quantídades de ácido lático, contribui para conferir ao produto um odor típico e agradável sabor; fol observado, também, que adicionando-se à massa do produto culturas "starters" de LACTOBACILIUS (plantarum, brevis, fermenti), o produto adquire melhor qualidade e seu tempo de maturaçăo é diminuído.

Sobre como estas bactérias chegam ao produto, existem várias teorias: a hipótese de que os Lactobacillus chegam à car- ne dos suinos através do intestino pode ser afastada, segundo MASCHERPA 11 (1965), tendo em vista que os Lactobacillus isolados do tubo digestivo de suínos não resistem às concentraçōes mais elevadas de $\mathrm{NaCl}$; o mais provável, segundo ele, é que estas bactérias chegam aos produtos provenientes de contaminação externa, pois existem no solo, na água, no ar e nas plantas e, encontrando condições adequadas desenvolvem-se rapidamente.

Certo é, entretanto, que não só germes dos gêneros LACTOBACILlus e Micrococcus, possuem relevante importáncia nos fenômenos metabólicos que se desenvolvem durante a maturaçāo de produtos cárneos, mas também outros desempenham papel de relevo, tendo sido pesquisados no sentido de serem adicionados à massa dos embutidos, em culturas puras. Nesse sentido, DEIBEL \& \& NIVEN (1957), estudaram - comportamento de espécies de Pediococcus (Pediococcus cereviseae) e verificaram sua atuaçāo na cura de salsichas, propugnando pela utilização desses germes, associados a outros, com o propósito do estabelecimento de culturas "starters".

O género Pedrococcus tem, pois, influência decisiva sobre as transformaçōes metabólicas na fase de maturação dos produtos cárneos, sendo exclusivamente pesquisada essa propriedade, como comprovam os trabalhos de PEDERSON 13 (1949) ; DELWICHE s (1958); e GUNTHER (1959).

Por outro lado, CATE 2 (1960), assinalou a presença e a importáncia do STREPTococcus sp., até o 16.0-18.0 dia de maturaçāo, concluindo que a principal açāo correlaciona-se à produção do aroma que caracteriza os produtos.

Mas, como referimos anteriormente, não só $o$ aspecto tecnológico deve merecer atenção; ○ de saúde pública destaca-se, por vezes, como assinala GIANELLI \& (1963), que preocupou-se, além da presença de clementos do grupo coli, com a presença de germes patogénicos, chegando mesmo à identificação de representantes do gênero STaPHYLococcus nos produtos embutidos. 
RICCETTI, R. V. et al. - Flora contaminante dos produtos embutidos de carne, tipo salame, com especlal referencia aos microrganismos do genero Lactobacillus (Beljerinck, 1901) R6v. Fac. Med. vet. Zootec. Univ. S. Paulo, 8:93-106, 1972.

Podc-se dai, aquilatar a flagrante complexiclade que envolve o problema da maturaçāo dos produtos cárneos embutidos, tanto no que diz respeito às alteraçóes inerentes a contaminação do produto como, e principalmente, no relativo à variada gama de fenómenos bioquimicos provenientes da intervençāo de elevado número de espécies microbianas, do meio ambiente, dos fatores físicos e químicos, aliados, por sua vez, à variada composiçăo da matéria-prima.

Todos esses fenómenos, agravados, de um lado, pelos inúmeros fatores que os modificam $e$, por outro, pelo fato de se processarem simultaneamente, justificam a preocupação de higienistas e tecnologistas no que concerne à elaboração de produtos $\mathrm{em}$ butidos de carne, razōes que nos moveram a tentar colaborar para o enriquecimento da literatura nacional especializada nesse assunto.

\section{MATERIAL E METODOS}

A amostragem para o presente trabalho foi representada por um embutido de carne, de fabricação típica, cuja matéria-prima é constituida por carne de suino e conhecido no comércio pela denominação de salame tipo salaminho. $O$ produto era remetido de um frigorifico situado na cidade de Ėrexim, RGS, através do Serviço de Inspeço Federal, de tal sorte que as amostras chegadas ao laboratorio tinham sempre a mesma idade. Para efeito de homogeneização das amostras, estabeleceu-se a primeira semeadura sempre no quinto dia de idade das mesmas. Para se calcular a evolução da flora bacteriana total, ao longo do periodo de maturaçăo, foi necessário remeter as amostras sempre em sextuplicatas, as quais pertenciam, rigorosamente, à mesma partida. Foram efetuadas dez coletas, num espaço de tempo, da primeira à décima, de 22 meses, realizadas nas datas abaixo discriminadas:

\begin{tabular}{|c|c|c|}
\hline Coleta & N.o de Pecas & $\begin{array}{c}\text { Data da che- } \\
\text { gada ao labo- } \\
\text { ratório }\end{array}$ \\
\hline $1 . a$ & 6 salaminhos & 3- 5-68 \\
\hline $2 . \mathrm{a}$ & 6 salaminhos & 7- 7-68 \\
\hline 3.2 & 6 salaminhos & 5- 9-68 \\
\hline $4 . a$ & 6 salaminhos & $6-11-68$ \\
\hline $5 . \mathrm{a}$ & 6 salaminhos & 8- 1-69 \\
\hline $6 . \mathrm{a}$ & 6 salaminhos & 5- $3-6 \theta$ \\
\hline $7 . a$ & 6 salaminhos & $5-5-69$ \\
\hline $8 . a$ & 6 salaminhos & 2- 7-69 \\
\hline $9 . \mathrm{a}$ & 6 salaminhos & 3- 9-69 \\
\hline 10.2 & 6 salaminhos & $6-11-69$ \\
\hline
\end{tabular}

De cada coleta, composta por 6 salaminhos, eram efetuadas 6 (seis) semeaduras, aos $5,10,20,30,40$ e 50 dias, seguindo-se a técnica habitualmente utllizada para o controle bacteriológico de produtos embutidos, ou seja, o primeiro salaminho era assepticamente incisado transversalmente ao meio, e retiradas pequenas porços do centro, num peso constante de 10 gramas, transportadas para um corpo de liquidificador que continha $90 \mathrm{ml}$ de soluto fisiológico esterilizado. Mantinha-se sob trituraçāo por trés minutos e, imediatamente, procediam-se a diluiçóes do material. Eram semeadas triplicatas de placas, no meio de CORETTI \& SOMOGYI 3 (1965), cuja formula percentual ê a seguinte:

$\begin{array}{ll}0,8 \mathrm{~g} & \text { Peptona de Caseina } \\ 0,8 \mathrm{~g} & \text { Peptona de Carne } \\ 0,6 \mathrm{~g} & \text { Extrato de Levedura } \\ 0,1 \mathrm{ml} & \text { Tween } 80 \\ 2,0 \mathrm{~g} & \text { Glucose } \\ \mathbf{0 , 0 5} & \text { de Amido solúvel } \\ \mathbf{0 , 5} \mathrm{g} & \text { de Cloreto de Sódio } \\ 0,003 \mathrm{~g} & \text { Sulfato de Manganés } \\ 0,06 \mathrm{~g} & \text { Sulfato de Magnésio } \\ 0,5 \mathrm{~g} & \text { Acetato de Sódio } \\ 1,6 \mathrm{~g} & \text { Agar } \\ \mathbf{1 0 0} \mathrm{ml} & \text { Agua destilada }\end{array}$


RICCETTI, R. V. et al. - Flora contaminante dos produtos embutidos de carne, tlpo salame, com especial referencla aos microrganlsmos do genero Lactobacillus (Beljerlnck, 1901) Rev. Fac. Med. vet. Zootec. Univ. S. Paulo, 8:93-106, 1972.

Prontas as semeaduras, as placas eram transportadas para estufas a $37^{\circ} \mathrm{C}$, por 48 horas, prazo apos o qual registrava-se a contagem global de germes, utilizando-se o contador de colônias tipos "Spencer" e computando-se pela média logaritmica.

Das placas contáveis, era extraído um número de colónias correspondente à ralz quadrada do total das mesmas, e repicadas isoladamente em meio de CORETTI \& SOMOGYI 3 (1965), liquido, cuja formula é a mesma do meio sólido, somente com ausência do agar. Dos tubos que apresentavam turvação, eram confeccionadas lâminas, coradas pelo método de GRAM, com a finalidade de identificar-se morfologicamente formas bacterians bacilares $c$ formas bacterianas cocóides. No $400^{\circ}$ dia do período de maturação, os tubos que haviam apresentado crescimento e identificados através das lâminas, como contendo representantes de formas bacilares, eram re-isolados (15 por amostra), incubados a temperaturas de $10,20,30,37,40$ e $45^{\circ} \mathrm{C}$, com intuito de classificar, através de seu ótimo de temperatura, LACTOBACILLUS dos grupos BETABACTERIUM, STREPTOBACTE-
RIUM e THERMOBACTERIUM, conforme calssificação proposta por ORLA-JENSEN 1: (1931). Uma vez definido este grupo, procediam-se às provas bioquimicas mais especificas, para uma tentativa de identificação de espécie. Os substratos utilizados foram compostos por Litmus-Milk, Nitrato, $\mathrm{NaCl} 2 \%, \mathrm{NaCl} 4 \% ; \mathrm{NaCl} 6 \%, \mathrm{NaCl} 8 \%$, Teepoll 0,4\%, Adonita, Arabinose, Celobiose, Dulcita, Galactose, Glicose, Inosita, Inulina, Lactose, Levulose, Maltose, Manita, D. manose, Melebiose melezitose, Rafinose, Ramnose, Sacarose, Salicina, Sorbita, Xilose e Arginina, cujos resultados encontram-se nas Figuras números 7 e 8 .

\section{RESUltados}

Os primeiros resultados a serem considerados, referem-se ao gradiente da flora bacteriana total aeróbica facultativa, ao longo do período de maturação. Esses dados compōem as Figuras n.o 1, 2 e 3 . Relativamente ao encontro percentual de $\operatorname{cocos}$ e bacilos, durante as fases de maturação estudades, as Figuras 4 e 5 evidenciam tais eventos.

FIGURA N.॰ 1 - Computo global de bactérlas aeróblas facultativas (a $37^{\circ} \mathrm{C}$ ) por grama, segundo a evolucăo do perlodo de maturacăo.

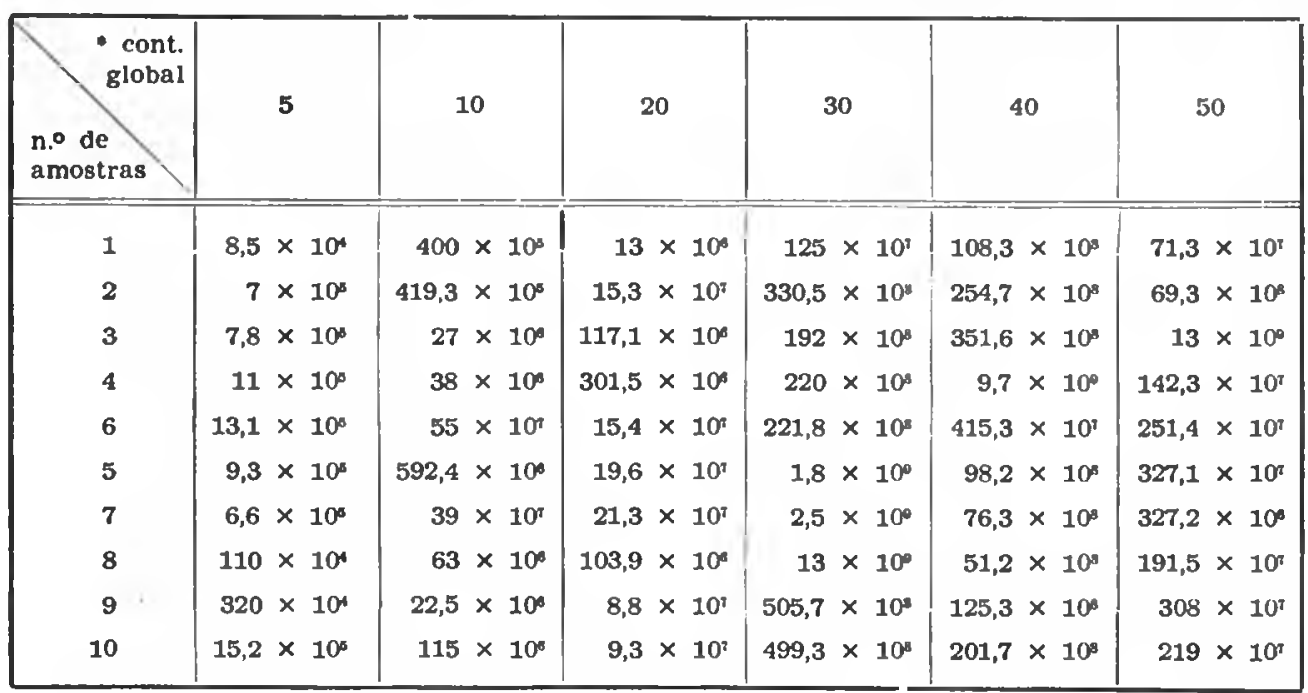

- Contagem global bactérias grama/das de maturaçao. 
RICCETTI, R. V. et al. - Flora contaminante dos produtos embutidos de carne, tipo salame, com especial referência aos microrganismos do gênero Lactobacillus (Beijerinck, 1901) Rev. Fac. Med. vet. Zootec. Univ. S. Paulo, 9:93-106, 1972.

FIGURA N.0 2 - Valores medianos $(x / 10)$ e correspondentes logaritmicos, referentes a quantidade global de germes aeróbios racultatlvos (figura n.o 1), segundo a evoluçăo do periodo de maturaçao

\begin{tabular}{c|r|r|r}
\hline $\begin{array}{c}\text { Contagem } \\
\text { global } \\
\text { bact/g }\end{array}$ & $\begin{array}{c}\text { Medianas } \\
(\mathrm{x})\end{array}$ & $\begin{array}{r}\text { Medianas: } \\
10(\mathrm{x} / 10)\end{array}$ & $\begin{array}{l}\text { Log. } \\
\mathrm{x} / 10\end{array}$ \\
\hline Dlas & & & \\
\hline \hline 5 & 1.015 .000 & 101.500 & 5,00647 \\
10 & 48.465 .000 & 4.846 .500 & 6,68538 \\
20 & 135.050 .000 & 13.505 .000 & 7,13033 \\
30 & 10.325 .000 .000 & 1.032 .500 .000 & 9,01368 \\
40 & 20.600 .000 .000 & 2.060 .000 .000 & 9,31175 \\
50 & 2.052 .500 .000 & 205.250 .000 & 8,31218 \\
\hline
\end{tabular}

O ótimo de temperatura pesquisado para as formas bacilares, isoladas à partir de $40 .^{\circ}$ dia de maturação, aparece ilustrado na Figura n. 6 .

A análise das cepas isoladas, realizada com o intuito de identificá-las quanto ao seu bioquimismo foi efetuada conforme descrito no capítulo de Material e Métodos e apresentaram os resultados constantes das Figuras n.os 7 e 8 . 
FIGUKA N: 3 - Contagem global de germe aeróbion (acultativos, por grama( $\left.\log \frac{x}{10}\right)$, segunde 17.

- 5\%, $10 \%, 209,30 \%, 40 \%, 50$ \% dial de maturaçăo.

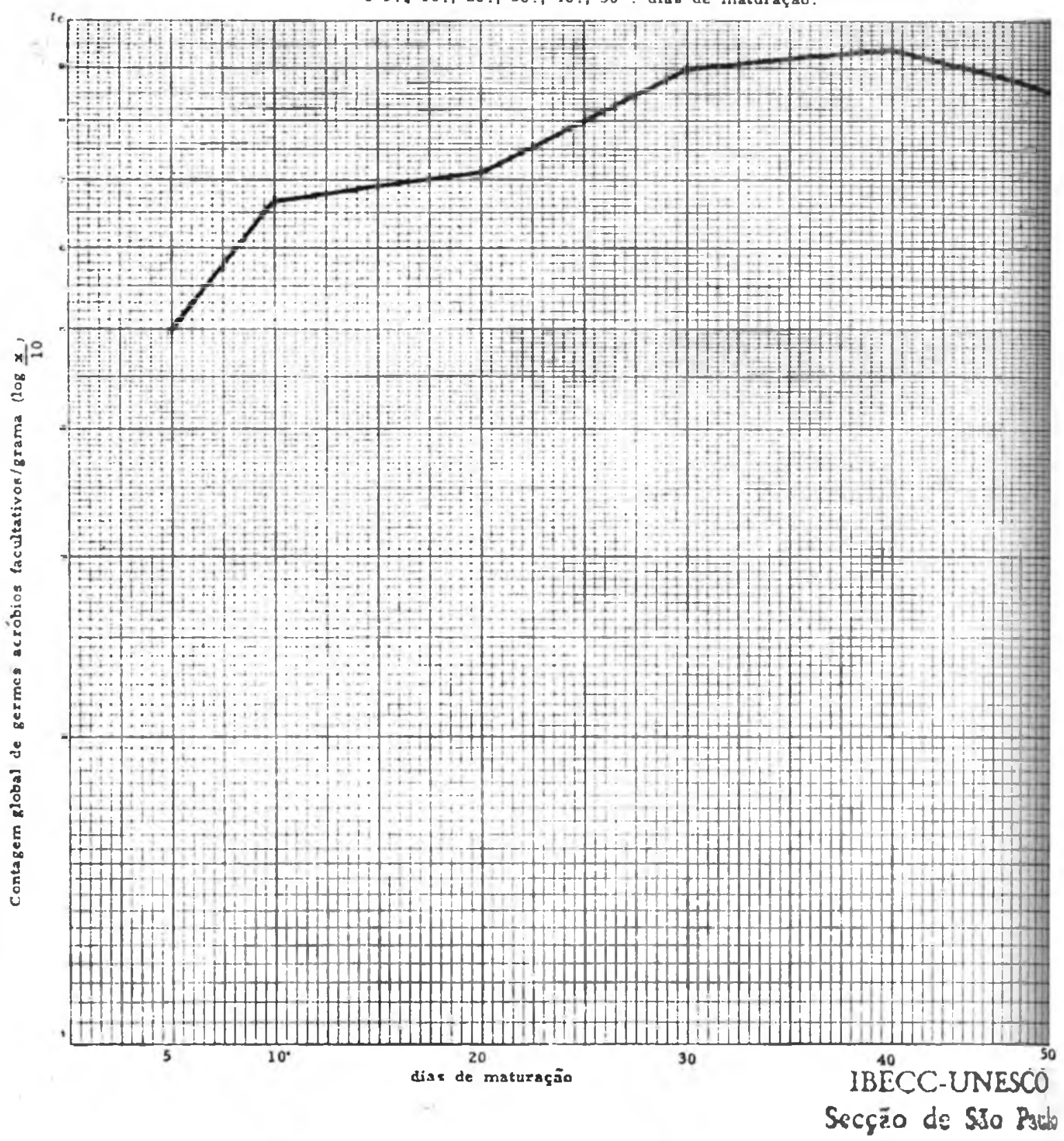


RICCETTI, R. V. et al. - Flora contaminante dos produtos embutldos de carne, tjpo salame, com especial referencla aos microrganismos do genero Lactobacillus (Beljerinck, 1901) Rev. Fac. Med. vet, Zootec. Univ. S. Paulo, 9:93-106, 1972.

FIGURA N.0 4 - Número de laminas estuàadas de 10 diferentes amostras de salame (tipo salaminho), segundo periodo de maturaç̄o e o correspondente encontro de formas cocóldes ou bacllares.

\begin{tabular}{|c|c|c|c|c|c|c|c|c|c|c|c|c|}
\hline \multirow[b]{2}{*}{ amostras it } & \multicolumn{2}{|c|}{$\mathbf{5}$} & \multicolumn{2}{|c|}{10} & \multicolumn{2}{|c|}{20} & \multicolumn{2}{|c|}{30} & \multicolumn{2}{|c|}{40} & \multicolumn{2}{|c|}{50} \\
\hline & C & $\mathbf{B}$ & C & $\mathbf{B}$ & C & $\mathbf{B}$ & C & $\mathbf{B}$ & C & $\mathbf{B}$ & C & $\mathbf{B}$ \\
\hline 1 & $\mathbf{9}$ & 6 & 8 & 7 & 2 & 13 & 1 & 14 & - & 15 & - & 15 \\
\hline 2 & 12 & $\mathbf{3}$ & 10 & 5 & 3 & 12 & - & 15 & - & 15 & - & 15 \\
\hline 3 & 10 & 5 & 11 & 4 & 1 & 14 & 2 & 13 & 1 & 14 & - & 15 \\
\hline 4 & 13 & 2 & 10 & 5 & - & 15 & - & 15 & - & 15 & - & 15 \\
\hline 5 & 12 & 3 & 9 & 6 & 2 & 13 & - & 15 & 1 & 14 & - & 15 \\
\hline 6 & 11 & 4 & 7 & 8 & 1 & 14 & 1 & 14 & - & 15 & - & 1 \\
\hline 7 & 15 & - & 8 & 7 & 4 & 11 & - & 15 & - & 15 & - & 1 \\
\hline 8 & 14 & 1 & 5 & 10 & 3 & 12 & 3 & 12 & 2 & 13 & - & 16 \\
\hline 9 & 12 & 3 & 13 & 2 & 2 & 13 & - & 15 & 1 & 14 & - & 5 \\
\hline 10 & 14 & 1 & 9 & 6 & 4 & 11 & 2 & 13 & - & 15 & - & 5 \\
\hline
\end{tabular}

FIGURA N.o 5 - Representaço grálica dos dados computados na FIGURA N.0 4

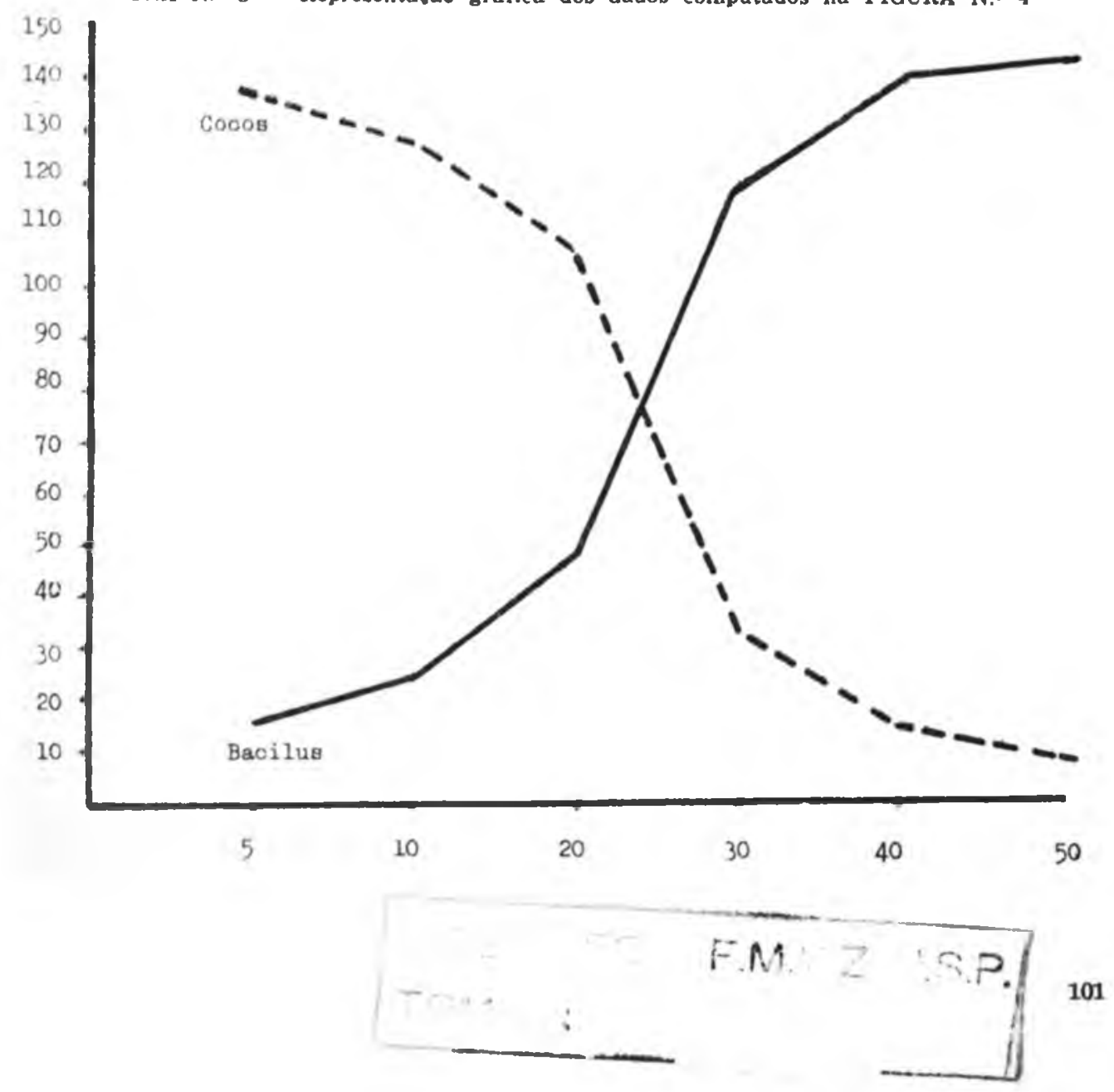


RICCETTI, R. V. et al. - Flora contaminante dos produtos embutidos de carne, tipo salame, com espectal referêncía aos microrganismos do gênero Lactobacillus (BcijerInck, 1901) Rev. Fac. Med. vet. Zootec. Univ. S. Paulo, 9:93-106, 1972.

FIGURA N.0 6 - Otimo de temperatura referente às formas bactlares isoladas à partir do $400^{\circ}$ dia de maturaçăo. -24 hs.

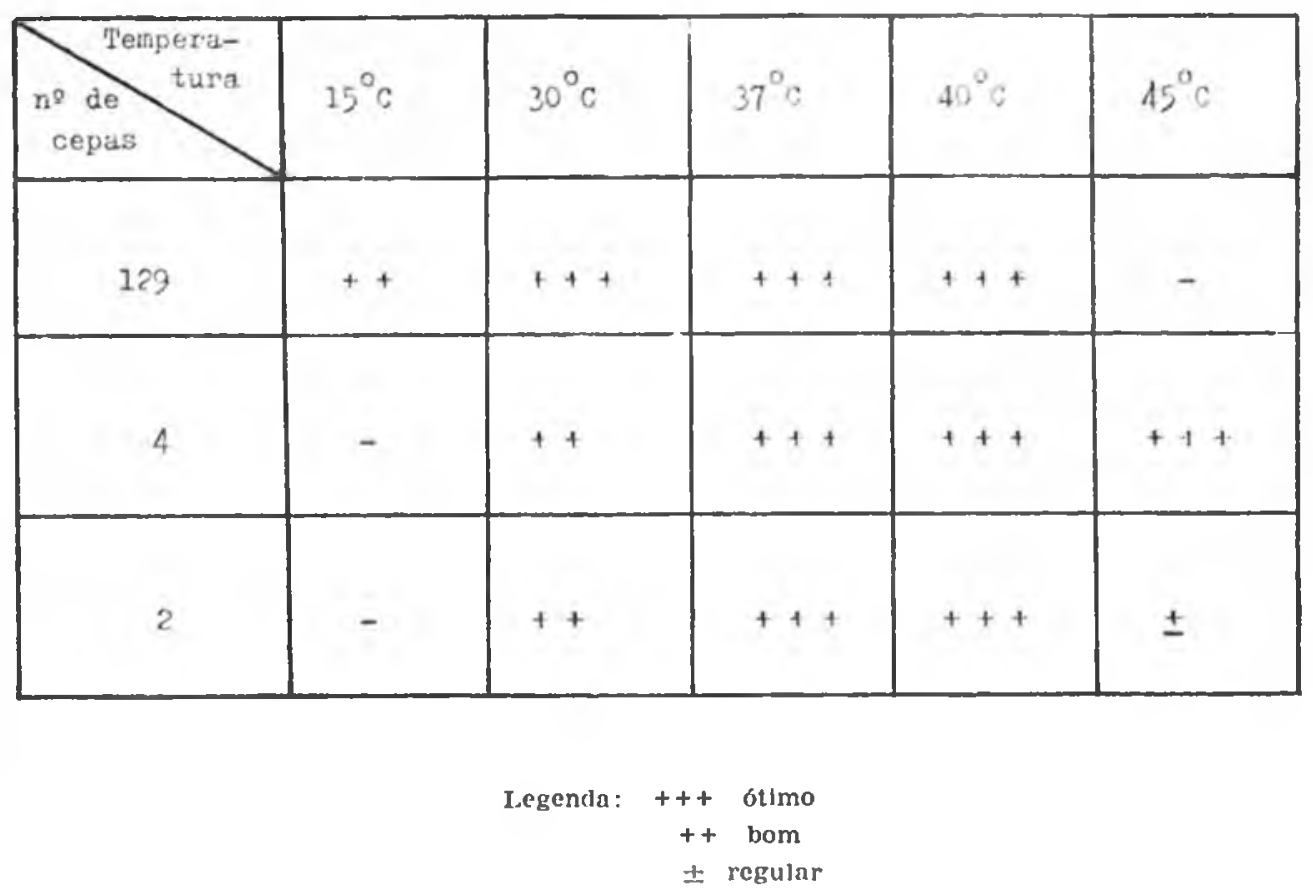


RICCFTTI, R. V. et al. - Flora contaminante dos produtos embutidos de carne, tipo salame, com especlal referêncla nos microrganismos do gênero Lactobacillus (Beljerinck, 1901) Rev. Fac. Mell. vet. Zoolec. Univ. S. Paulo, 9:93-106, 1972.

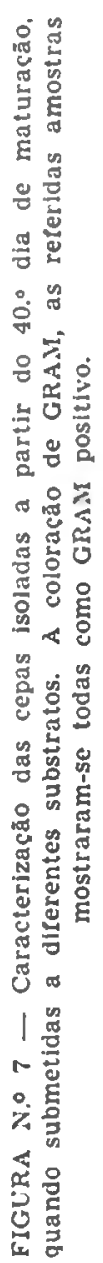

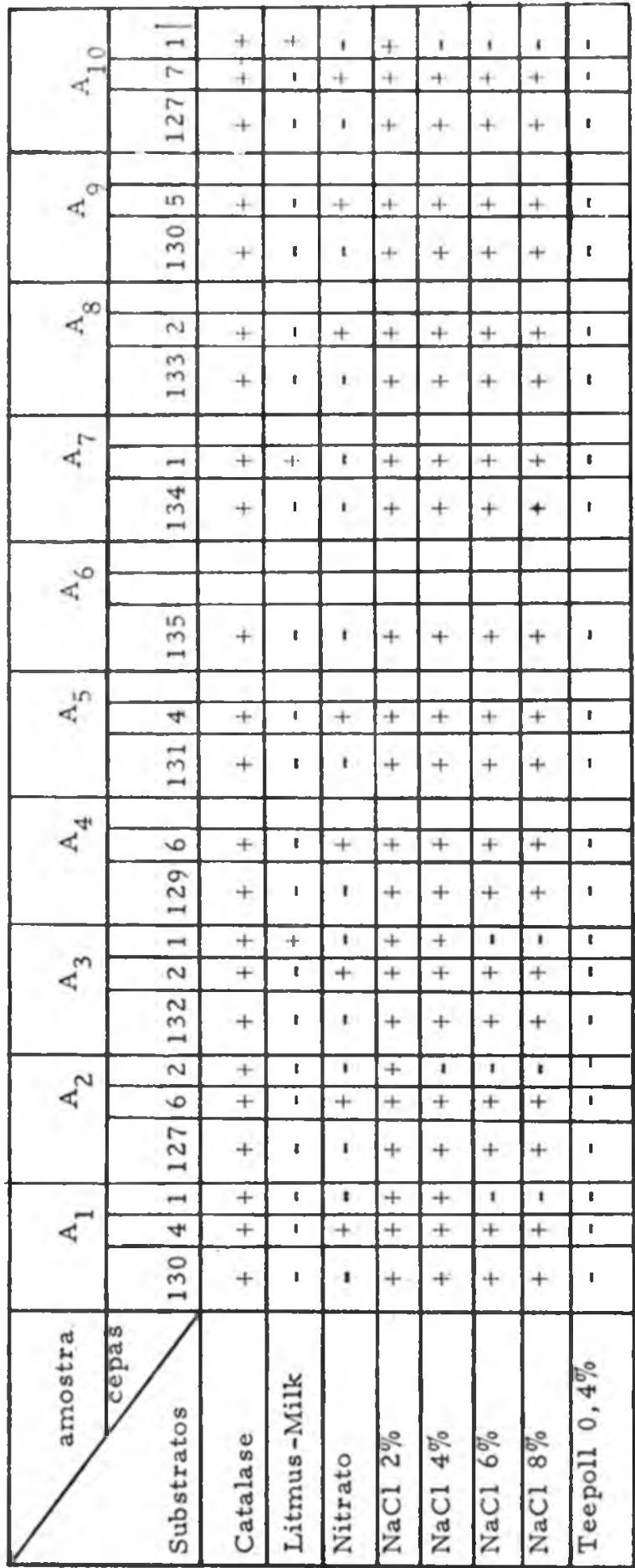


RICCETTI, R. V. et al. - Flora contaminante dos produtos embutidos de carne, tipo salame, com especlal referencia aos microrganismos do gênero Lactobacillus (Beljerinck, 1901) $R \rho v$. Fac. Med. vet. Zootec. Univ. S. Paulo, 9:93-106, 1972.

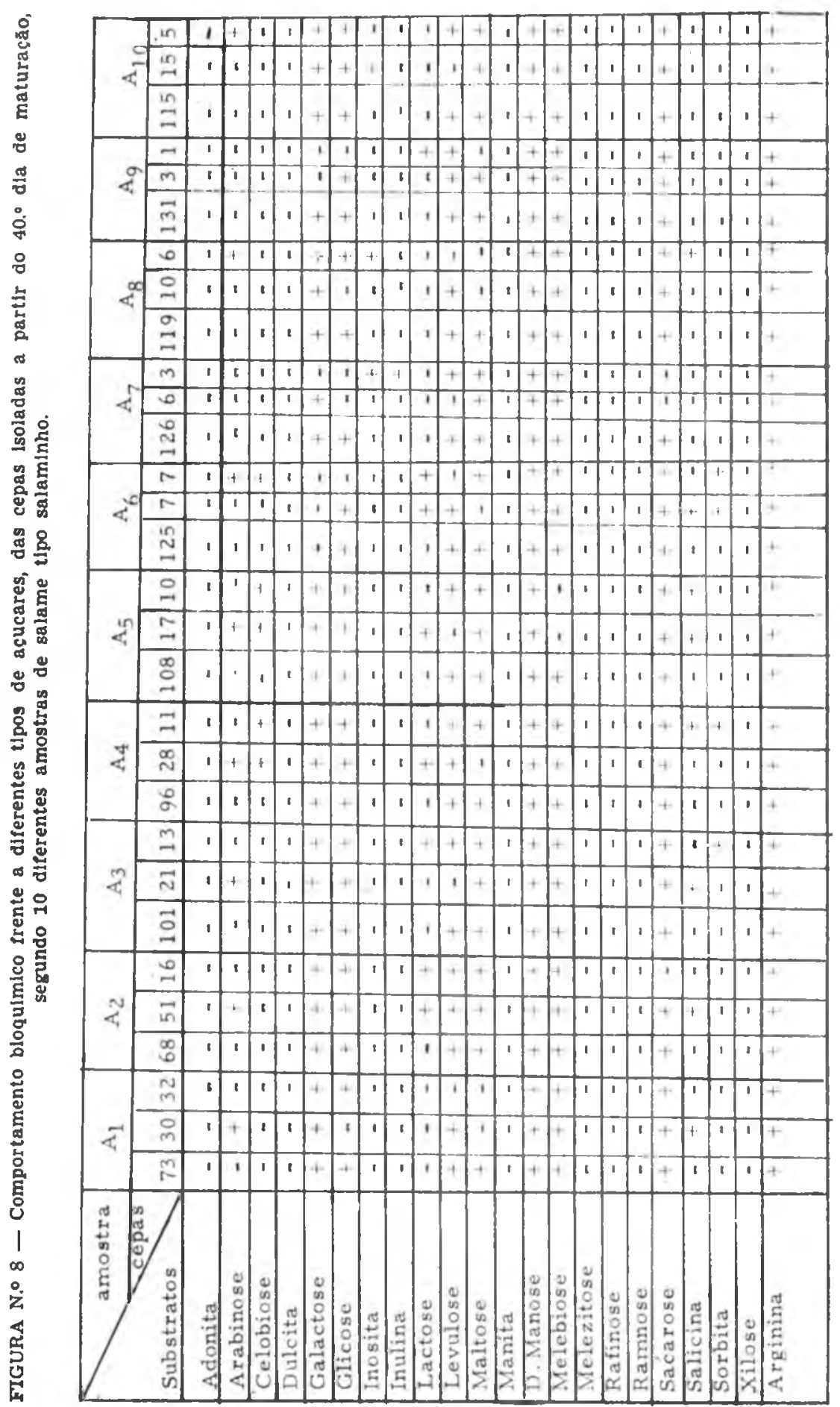


RICCETTI, R. V. et al. - Flora contaminante dos produtos embutidos de carne, tipo salame, com especial referênclá aos microrganismos do gennero Lactobacillus (Belferinck, 1901) Rev. Fac. Med. vet. Zontec. Univ. S. Paulo, 9:93-106, 1972.

\section{ร. DISCUSSXO}

Parece, pelo que ficou demonstrado nos capitulos anteriores, constatada a importância do conhecimento das espécies úteis que ocorrem nos produtos embutidos e, particularmente, sua atuação especifica sobre os substratos bioquímicos desses produtos, originando transformaçôes que culminam com o estabelecimento de sabor, aroma e textura especificos, que qualificam tecnológica e sanitariamente tais alimentos. $\mathrm{E}$ fundamental esse conhecimento no que concerne aos achados em nosso ambiente, pois como parece comprovado, a ocorrência de diversas espécies microbianas nesse tipo de alimento, tanto pode melhorá-lo, como piorá-lo, na dependência das estirpes envolvidas e do seu número.

a presença de Lactobacillus nos produtos citados, dentro de certos limites, parece ser sempre benéfica, pois é responsável pelas caracteristicas tāo ansiosamente procuradas pelo consumidor, quais sejam, o sabor, o aroma e a textura. MASCHERPA 10 (1965).

Neste sentido, dois aspectos devem ser considerados. Um, de ordem higiênica e outro de ordem tecnológica, pois é sabido que contaminaçōes excessivas por germes banais têm a propriedade de dificultar a multiplicação de representantes do gênero LAcTOBACILLus. Este fato é facilmente caraceterizado, se estudarmos, à luz dos dados fornecidos por autores estrangeiros GIOLITTI \& MASCHERPA o 1965), os nossos, no que concerne à evolução do desenvolvimento de LACTOBACILLUS. Quando a contaminaçāo é baixa, verifica-se que o ápice da quantidade desses microrganismos é muito mais rapidamente atingido do que quando a contaminação é elevada. Ora, isto envolve um problema tecnológico, pois se os LACTOBACILlus custam a se desenvolver e atingir o ápice, isto significa que o periodo de maturação se prolongará demasiadamente, consumindo um periodo de tempo precioso, quando considerado o problema do ângulo econômico.
Nesse sentido é importante considerar os estudos de MASCHERPA 11 (1965), o qual, ao analisar o fato citado, conclui que o cume do desenvouvimento de LACTOBACILLUS é atingido ao redor do $300^{\circ}$ dia de maturaçāo, ao passo que em nosso meio esse ponto é alcançado como comprova a figura n. 5 , somente ao redor do $500^{\circ}$ dia de maturação. Ora, o período de tempo correspondente a essa diferença representa, em última análise, dois problemas graves; de um lado a permanência inútil do produto em câmaras de maturação, quando ele poderia ser dado ao consumo muito mais rapidamente e outro, o que é mais importante, o fato envolve, dedutivamente, um problema higiênico clos mais sérios, pois esse prolongamento da maturaçāo evidencia uma excessiva contaminação por germes inúteis, angariados nas diversas fases de manipulação.

Ora, a adição de "starters" de culturas puras de Lactobacillus, no momento da elaboraçāo dos produtos, vem fatalmente reduzir, através do estabelecimento da concorrência vital entre os microrganismos, o periodo de maturação dos produtos através da eliminação de concorrentes inúteis. Mas, para que seja viável tal situação, é necessário estabelecer espécies de LactoBacrllus mais freqüentemente detectadas nos produtos nacionais já que existe uma variedade muito grande desses germes, os quais possuem comportamento bioquímico altamente complexo. As tentativas que fizemos para o estabelecimento da identificação dessas espécies, talvez colabore para estudos futuros mais detalhados sobre esse genero.

\section{CONCLUSOES}

1. Os logaritimos $(x / 10)$, correspondentes aos números bacterianos totais por grama, encontrados no $50^{\circ} .10 .^{\circ}, 200^{\circ}, 30.0$, $500^{\circ}$ dia de maturação de salames tipo salaminho correspondem, respectivamente, a 5,$00647 ; 6,68538 ; 7,13033 ; 9,01368 ; 9,31175$ e 8,31218 . 
RICCETTI, R. V. et al. - Flora contaminante dos produtos embutidos de carne, lipo salame, com especial referencla aos microrganismos do gênero Lactobacillus (BejJerinck, 1901) Rev. Fac. Med. vet. Zootec. Univ. S. Paulo, 9:93-106, 1972.

2. A partir do $100^{\circ}$ dia de maturaçāo, é evidente um decréscimo pronunciado das formas cocóides e uma ascençāo simultânea das formas bacilares, que atingem um máximo de desenvolvimento ao redor do $500^{\circ}$ dia de maturação.

3. 129 das $\mathbf{1 3 5}$ cepas estudadas apresentaram um otimo de temperatura entre $30^{\circ} \mathrm{C}$ c $40^{\circ} \mathrm{C}$, apresentando crescimento maior a $15^{\circ} \mathrm{C}$ e ausência de crescimento a $45^{\circ} \mathrm{C}$, fato que, segundo ORLA-JENSEN 12 (1931), identifica-as com pertencentes ao grupo STREPTOBACTERIUM.

4. O otimo de temperatura, considerado simultaneamente com o comportamento bioquímico da maioria das cepas estudadas, parece indicar a supremacia, respectivamente, das espécies CASEI var. ALACTOSUS e PLANTARUM.

5. Dada a complexidade do comportamento bioquímico das espécies do gênero LACTOBACILLUS, impōe-se um estudo mais detalhado acerca de suas caracteristicas frente a diferentes substratos, para uma perfeita identificação das espécies.

RFMVA-7

RICETTI, R. V. et al. - Subsidies to the knowledge of the useful flora responsible for the maturation of sausage products, of the salame type. Rev. Fac. Med. vet. Zootc. Univ. S. Paulo, 9:93-106, 1972.

SUMMARY - Contributing to the study of the contaminating flora of meat products, specially those classified as salami, the uthors studied the microrganisms belonging to the genus Micrococcus and Lactobacillus, considered important to thematuration's process of these products. Among other conditions it was established: 1) the numerical evolution of these microrganisms during the different steps of maturation, 2) the preponderance of the species of these genus, 3) the ideal temperature, considered simultaneously with the biochemical behaviour of the strains' majority.

UNITERMS: Salame*; Sausage *; Maturation *.

\section{REFERENCIAS BIBLIOGRAFICAS}

1. BREED, R. S. et al. - Bergey's manūal of determinatlve bacteriology. 7th ed. Baltimore, Williams \& Wilkins Co., 1957.

2. CATE L., T. - apud GIOLITTI, G. \& MASSACRA, G. " p. 542.

3. CORETTI, K. \& SOMOGYI, A. - Manganese sulphate-sodium acetate medlum for culturing differentiation of lactobacllli in foods. Fleichwirtschaft, 45 (5) : 476-82, 1965

4. DeIBEI, R. I. \& NIVEN, C. F. - Pediocaccus cerviseae a starter culture for summer sausage. Bact. Proc.: 14-5, 1957.

5. DELwiche, E. A. - Catalase of Pediococcus cerviseae. J. Bact., 81(3):4168,1961 .

6. GIANELII, F. - Rlcherche e considerazione sulla carlca batterica dell'impasto di salame tipo felino durante la staglonatura. Atti. Soc. Ital. Sci. vet., 7:631-63, 1953.

7. GIOLITTI G. - Ricerche sul processo dl maturazlone degli insaccati. Arch. vet. ital., $11(1-2): 23-31,1960$.

8. GIOLITTI, G. \& MASSACRA, G. - Ricerche sulla flora microbica degll insaccati. Atti Soc. Ital. Sct. vet., 17: 541-6, 1963.

9. GUNTHER, II. L. - Mode of division of Pediococcus. Nature, (Lond.), 183: $903,1959$.

10. MASChERPA, G. - I lattobacilll degli Insacatti staglonati. Arch. vet. ital., $16(2): 105-16,1965$.

11. NIINIVARA \& POIJA apud DEIBEL, R. II. et al. - Microblology of meat wering. IV A lyophllized Pediococcus cerviseae stater culture for fermented sausage. Appl. Microbiol, 9:243, 1961.

12. ORLA-JENSEN - Dairy bacteriology. 2th ed. London, J. \& A. Churchill, 1931.

13. PEDerson, C. S. - The genus Pediococcus. Bact. Rev., $19(1): 225-32,1949$.

14. SHARPE, M. E. \& FRYER, T. F. - Identification methods for microblologists indentlfication of the lactle acid bacterla. London, Sld. (Soclety for Applied Bacteriology Technical. Series, 1).

Recebido para publlcacão em 2-8-72 Aprovado para publicação em 3-10-72 